\title{
Relation of form to life habit in free-living cupuladriid bryozoans
}

\author{
Aaron O'Dea* \\ Smithsonian Tropical Research Institute, MRC 0580-01, Apartado 0843 - 03092, Panamá, República de Panamá
}

\begin{abstract}
Since the late Mesozoic, several bryozoan groups have occupied unstable soft-sediment habitats by adopting a free-living and motile mode of life. Today, the free-living bryozoans often dominate epibenthic faunal communities in these expansive habitats, yet their biology and ecology remain poorly understood. This study examines their unique mode of life by exploring the relationship between form and function in the free-living Cupuladriidae of tropical America. Cupuladriid species occupy distinct niches in water depth and sediment type, and these variables correlate with a variety of morphological traits amongst species, thereby helping formulate hypotheses on functional morphology. These hypotheses were tested with disturbance, burial and mobility experiments. Species deal both passively and actively with disturbance and burial. Colony size and shape passively influences colony stability on the sea floor, susceptibility to burial and the ability to emerge once buried. Movable mandibles (setae) assist in emergence following burial, actively increase colony stability, and deter the settlement and disruption of encrusting growth of other organisms. Mandibles also enable colonies to move over the sea floor, but such behaviour appears to be of minimal benefit to avoid predation or to influence dispersal. Disturbance on the sea floor is the most important factor in driving the convergent evolution of the mobile free-living form. Colony shape and size and the employment of mandibles to improve stability, return to the surface after burial, and remove epibiota are central to the post-Mesozoic success of free-living bryozoans.
\end{abstract}

KEY WORDS: Cupuladria spp. · Discoporella spp. · Lunulitiform $\cdot$ Realised niche $\cdot$ Life mode $\cdot$ Soft sediments $\cdot$ Disturbance $\cdot$ Form and function

Resale or republication not permitted without written consent of the publisher

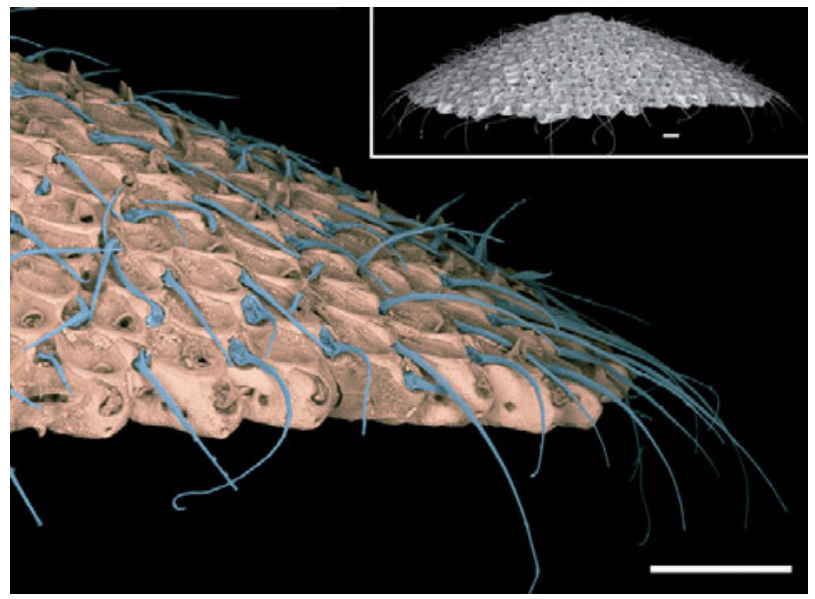

Colonies of free-living bryozoans dig to the surface using setae (blue) after being buried; this explains their long-term success on unstable sediments (scale bars: $500 \mu \mathrm{m}$ ).

False colour scanning electron micrograph: Aaron O'Dea \& Felix Rodriguez

\section{INTRODUCTION}

Most modern bryozoan species build encrusting colonies from replicated modules (zooids) that are fixed to a substrate such as a stone or another organism (Ryland 1970, McKinney \& Jackson 1989, Hageman et al. 1998). Others build erect colonies, branching upwards to escape constraints of life close to the substrate, yet they too remain rooted in one position and are thus subject to the limitations of a sessile life (Huey et al. 2002). In contrast, free-living bryozoans are unattached and rest freely on the seafloor (McKinney \& Jackson 1989). 

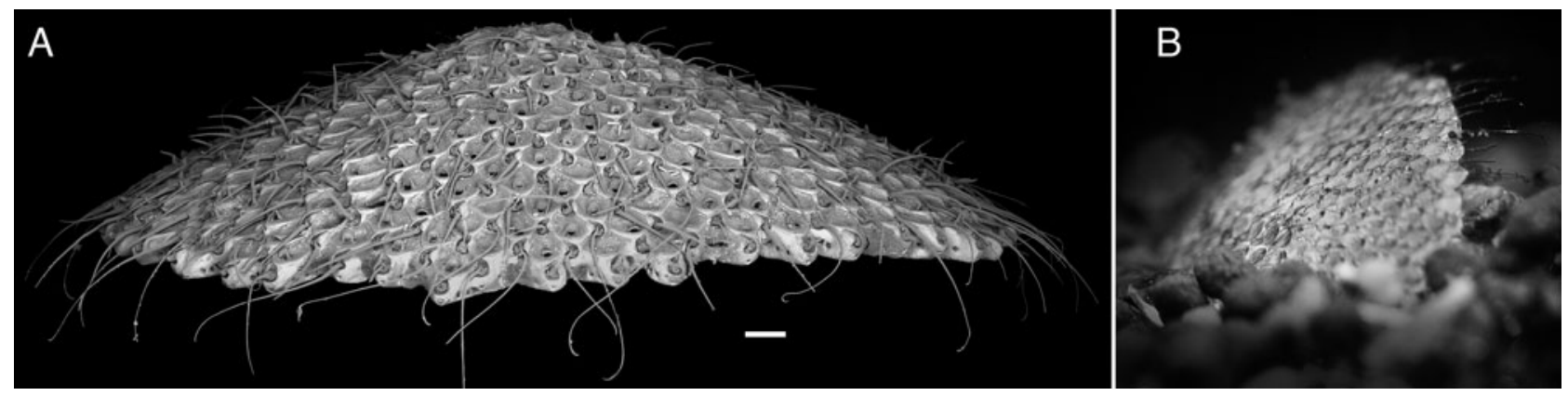

Fig. 1. Cupuladria spp. (A) Entire colony of C. biporosa in life position showing vibracula mandibles. (B) Living colony of C. exfragminis emerging from sediment following burial. Scale bar: $500 \mu \mathrm{m}$

Most free-living bryozoans were originally sessile, but during the late Mesozoic and early Cenozoic, members of the families Cupuladriidae and Lunulitidae adopted a mobile mode of life through the use of long tapering setae of polymorphic zooids termed vibracula (Lagaaij 1963, Cook \& Chimonides 1983, Winston 1988, McKinney \& Jackson 1989, Jackson \& McKinney 1990, Håkansson \& Voigt 1996). Despite being distantly related, Cupuladriidae and Lunulitidae share similar morphological, behavioural and anatomical characteristics, implying strong convergent evolution towards specialised adaptation to life on shifting sediments (Cook \& Chimonides 1983).

The free-living mobile mode of life (sometimes termed 'lunulitiform') became highly successful, as demonstrated by the rapid occupation of habitats around the world, increasing diversity, and high abundances of colonies from the Late Cretaceous to the present day (Lagaaij 1963, Cook \& Chimonides 1983, McKinney \& Jackson 1989, Jackson \& McKinney 1990, O'Dea et al. 2008). The underlying causes and evolutionary patterns of this success remain speculative. In this study, I explore the functional significance of the mobile freeliving form and habit by focusing on the family Cupuladriidae and relating the morphology of species to their niche habitats, life habits and behaviour.

\section{Biology and ecology}

The 2 free-living cupuladriid genera, Cupuladria and Discoporella, are closely related, but their common ancestor is unknown (Dick et al. 2003). Both genera share the same general body plan of small cupshaped colonies formed by radially-budded zooids (Fig. 1), but within this arrangement, sizes and shapes vary greatly between species. Some species form flat colonies whilst others are highly domed (Fig. 2). Domed colonies may have their bases filled-in by skeletal material, which makes them exceptionally strong (Fig. 2B), or they can be hollow and fragile (O'Dea et al. 2008). Colony growth is either, (1) 'determinate', identified by the closure of marginal zooids or the production of a terminal ring of non-feeding kenozooids, or (2) 'indeterminate', where colonies perpetually bud marginal zooids.

Each autozooid feeds using a lophophore and is paired with a non-feeding zooid called a vibraculum (Fig. 3) that has a long tapering mandible (seta) (Figs. 1A \& 4) that sweeps in a roughly disto-proximal plane across the face of the colony up to 180 degrees (Cook 1965). Mandibles from vibraculae situated at the colony margin curve outwards and downwards, lifting the colony slightly above the sea floor (Fig. 1).

Colonies are abundant when conditions permit, with densities of 1 to 10 colonies $\mathrm{m}^{-2}$ (Lagaaij 1963, Cadée

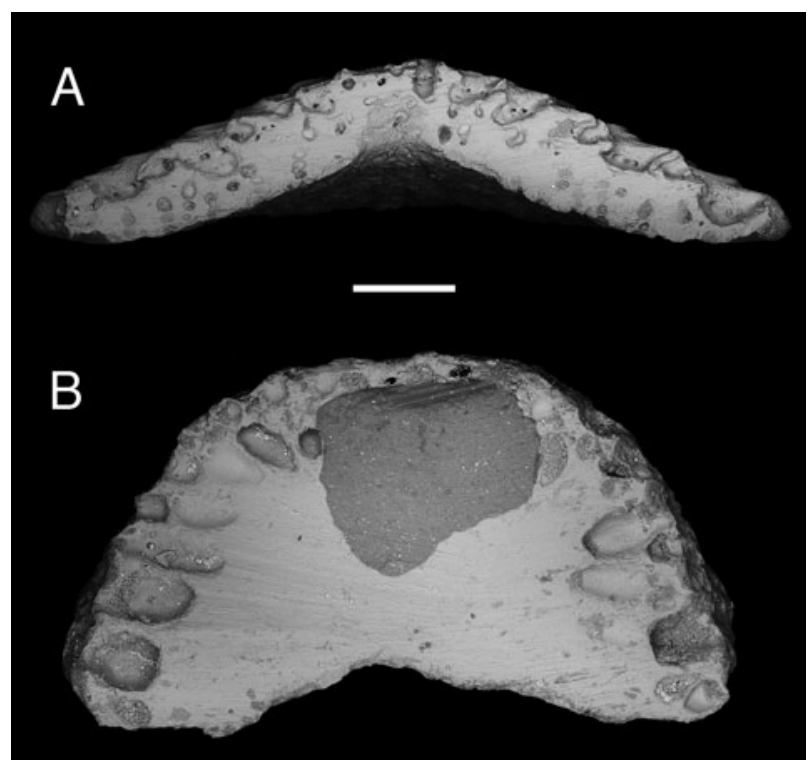

Fig. 2. (A) Cupuladria biporosa and (B) Discoporella triangula. Transverse section through the middle of a colony; dark centre in (B) is the sand grain upon which $D$. triangula settled. Scale bar: $500 \mu \mathrm{m}$ 


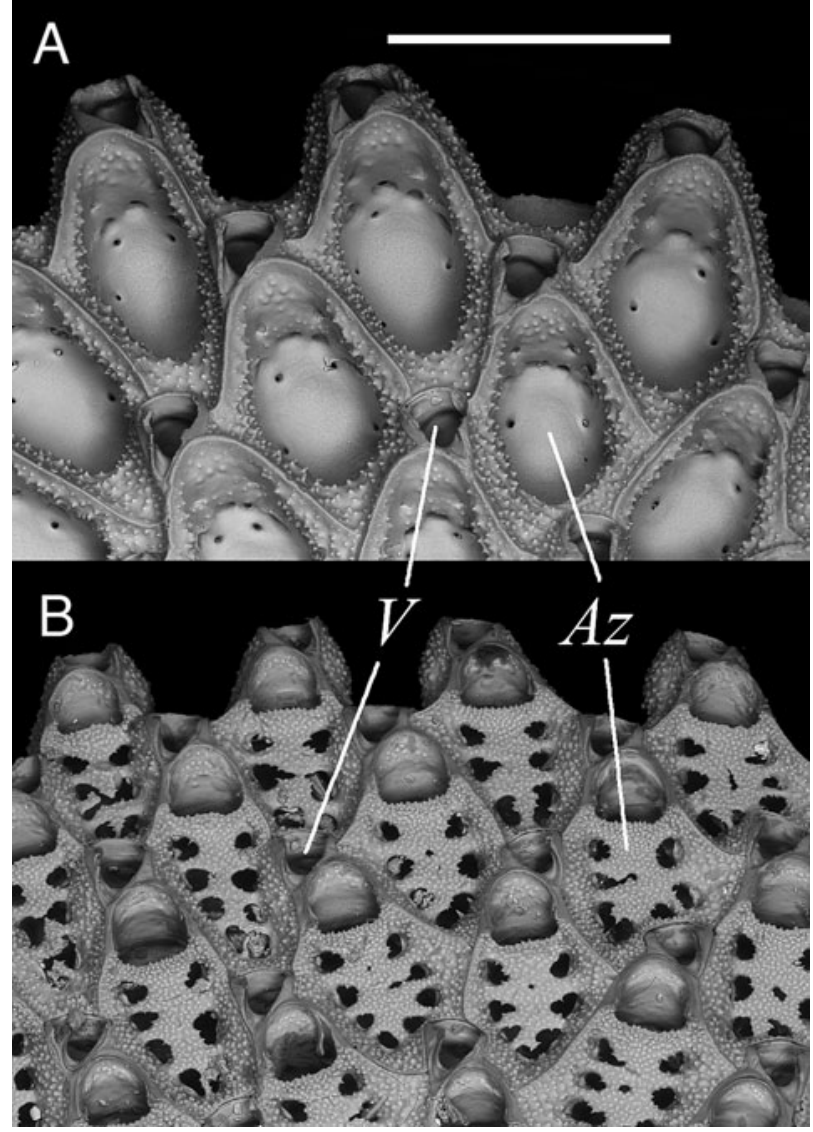

Fig. 3. (A) Cupuladria biporosa and (B) Discoporella bocasdeltoroensis. Marginal autozooids $(A z)$ and vibraculae zooids $(V)$. Scale bar: $500 \mu \mathrm{m}$

1975, Marcus \& Marcus 1962), a pattern frequently seen in the fossil record of sandy and silty Cenozoic deposits around the world (Cook \& Chimonides 1983, O'Dea et al. 2008).

Cupuladriids propagate both sexually and asexually (Dartevelle 1932, Baluk \& Radwanski 1977, Winston 1988, Thomsen \& Håkansson 1995, Håkansson \& Thomsen 2001). Sexual reproduction is via larvae that normally settle on a grain of sand or other small object (Driscoll et al. 1971, O'Dea et al. 2008) and metamorphose into the first 3 ancestral zooids. Budding extends the colony over the edge of the original substratum, at which point the colony becomes free-living. Asexual (clonal) propagation can occur in many ways (O'Dea et al. 2008), but all involve the breakage or separation of a part or parts of a colony, which then regenerate to form new colonies. Morphology is tightly coupled to mode of propagation. Small, robust colonies rarely fragment, and their colonies are sexually recruited; large, thinly calcified and indeterminately growing species tend to readily fragment, and their colonies are most often clonal (O'Dea et al. 2004).

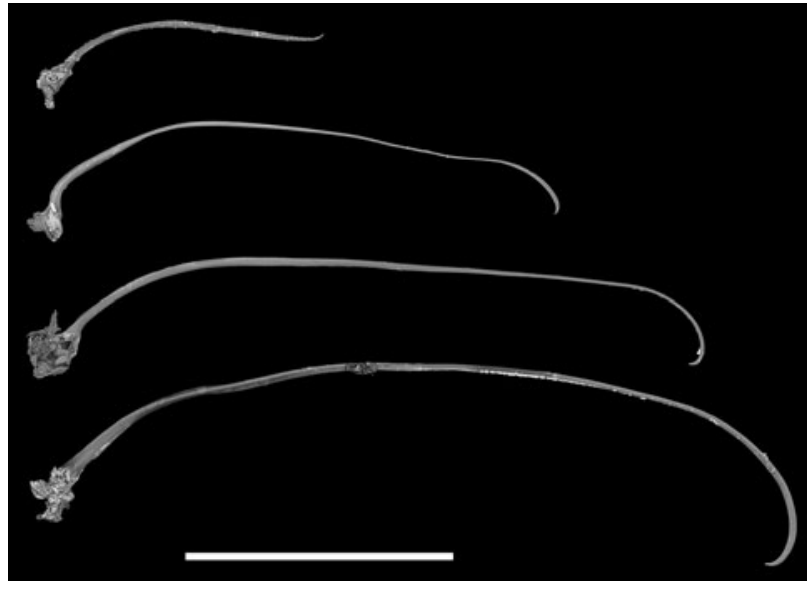

Fig. 4. Mandibles from marginal vibracula removed from large colonies of (from top to bottom) Cupuladria sp. nov. 'gigante', Discoporella terminata, C. exfragminis, and D. sp. nov. P1. Scale bar: $500 \mu \mathrm{m}$

Dispersal in encrusting bryozoans is thought to occur most commonly via colony rafting, because planktonic larvae are usually short-lived (Hoare et al. 1999, Porter et al. 2002, Keough \& Chernoff 1987). Cupuladriids do not encrust floating debris, making rafting an unlikely vector for dispersal, and the limited data available suggest that cupuladriids have particularly short-lived larvae (Cook \& Chimonides 1983, Winston 1988). Colonies are motile, but speed of movement may not be sufficient to influence rates of dispersal.

\section{Aims of the study}

This study compares data on habitats, modes of life and behaviour with morphometric data to explore adaptations of cupuladriids to soft-sediment epibenthic life. Specifically, I examined niche variation amongst cupuladriid bryozoans by measuring the abundance of different species along environmental gradients. The distributions of species in different environments are correlated with morphology to establish hypotheses on the relationship between form and function. The passive role of colony form and active colony behaviour on the stability of the colony on the sea floor was investigated. The relationship between morphology and colony strength was tested with consideration of life history. The importance of colony and zooid form on the behaviour of colonies above, and their behaviour and mortality below the sediment, was measured. All data were assessed in the context of the evolution of form and function of free-living bryozoans.

Although free-living bryozoans often dominate epibenthic faunal communities in soft-sediment shelf habitats across the tropics and have done so for much 
of the Cenozoic, their ecological importance is frequently overlooked. The mode of life adopted by freeliving bryozoans is unique amongst marine animals, as is the niche which they occupy, yet both remain drastically under studied.

\section{MATERIALS AND METHODS}

Distribution and habitats. The material used in the present study was the same collection of recent cupuladriid colonies used in an analysis of life history variation in species across the Isthmus of Panama (O'Dea et al. 2004). Since then, cupuladriid taxonomy has advanced (Herrera-Cubilla et al. 2006, 2008) and so each of the nearly 20000 colonies were re-classified to species level.

Cupuladriid colonies were collected from 193 dredge samples in soft bottom sediments along the Caribbean and Pacific coasts of the Isthmus of Panama (Fig. 5). All colonies were identified according to Herrera-Cubilla et al. $(2006,2008)$; see O'Dea et al. $(2004,2007)$ for collection methods.

At each dredge sample location, bottom sediment was sampled in triplicate using a Van Veen Grab. Mean percent calcium carbonate $\left(\mathrm{CaCO}_{3}\right)$ and mud fraction (proportion of sediment $<63 \mu \mathrm{m}$ ) were determined for the sediments at each location (data from O'Dea et al. 2007). To measure the distributions of each cupuladriid species along 3 environmental gradients (water depth, \% $\mathrm{CaCO}_{3}$ and \% mud), mean, median, quartiles, and 5 and 95 percentiles were calculated from the abundances of each species. Data were first normalised for uneven sampling intensities across the range of each environmental variable by grouping samples into bins and dividing the number of colonies of each species in each sample by the number of samples represented in the bin to which the sample belonged. For \% $\mathrm{CaCO}_{3}$ and \% mud fraction, 10 bins of equal size were constructed from 0 to $100 \%$. For water depth, 10 bins were constructed at 0-20, 20-40, $40-60,60-80,80-100,100-120,120-140$, 140-160, 160-200, and 200-400 m. Every bin for each variable contained at least one sample. Continuous distributions of colony abundance were converted to histograms, standardised within the histogram bins, and then reconverted to distributions to calculate mean, median, quartiles and percentiles.

Colony diameter, height and shape data were gathered for each species following the methods described in O'Dea et al. (2004), using 100 colonies randomly selected from the sampled population. All colonies were used if the total sampled population of a species was $<100$ colonies. Colonies used for morphometric analysis were weighed to determine mean calcification index for each species following the methods of O'Dea et al. (2004).

Mean zooid and vibraculum length, width and area (length $\times$ width) were determined for those species described in Herrera-Cubilla et al. $(2006,2008)$. Data on species yet to be described were determined by measuring 5 zooids and vibracula from 5 haphazardly selected colonies of each species. Mean length of marginal mandibles of species was determined from living colonies by removing 5 marginal mandibles in 5 colonies of each species and measuring their entire outstretched length. The largest colonies available of each species were used to reduce astogenetic or onto-

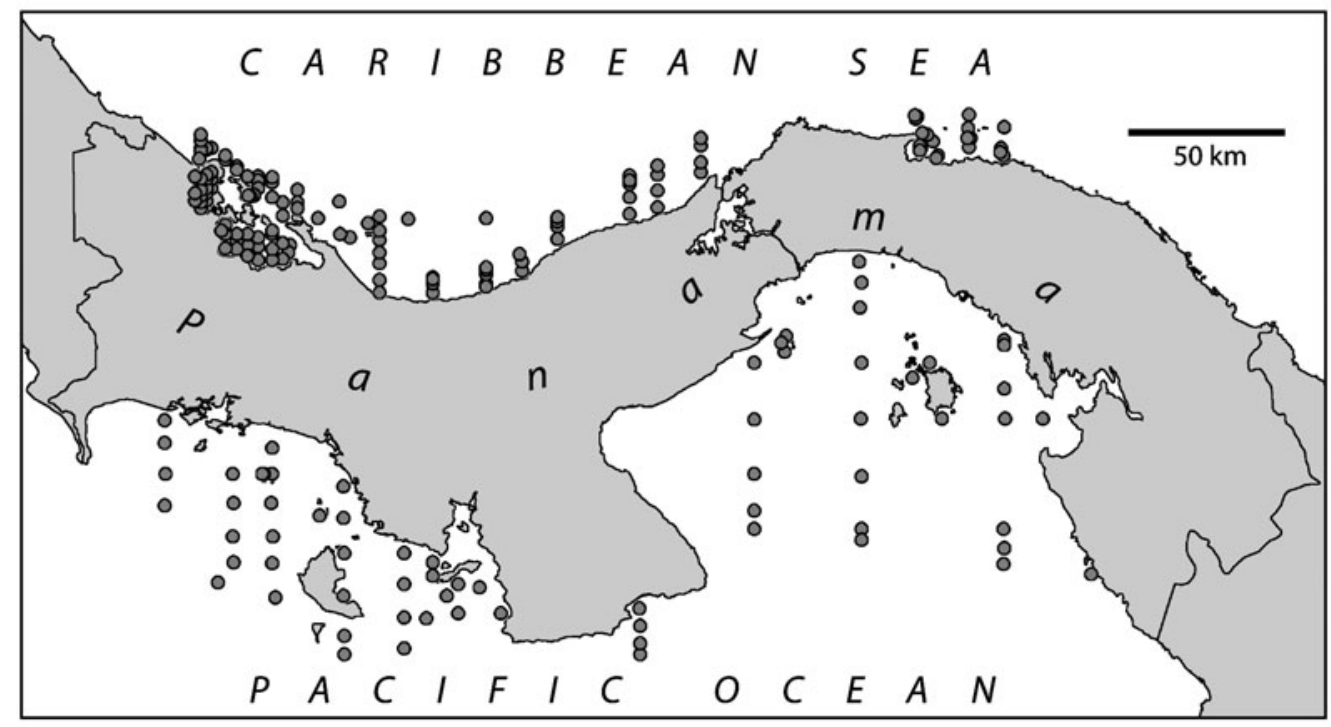

Fig. 5. Location of 193 dredge samples of Bryozoa in Pacific and Caribbean shelf seas off the Isthmus of Panama (see O'Dea et al. 2004) 
genetic influences upon mandible length and standardise the approach.

Distributions of species along environmental gradients (normalised mean and median water depth, \% $\mathrm{CaCO}_{3}$ and \% mud fraction) were correlated to colony and zooidal morphology to formulate theories on the function of cupuladriid morphology. Pearson product moment correlation coefficients (r) were calculated, and the significance of coefficients was determined by Student's $t$-test.

Orientation following disturbance. The effect of colony morphology on the orientation of colonies during times of disturbance was explored by measuring the response of 10 replicate colonies of 6 morphologically different cupuladriid species to repeated simulated disturbance events. In addition to the 6 species, fragmented colonies of Cupuladria biporosa were also analysed to observe how fragments differ from whole colonies during times of disturbance.

The experiment therefore comprised 7 groups of 6 species of whole colonies and 1 group of a species' fragments. For each group, 10 colonies were haphazardly chosen from dredge sample collections. All colonies used were dead and all species except one were from the Holocene. The fossil species Discoporella sp. nov. 3, which occurred in tropical America during the Pliocene and is now extinct (O'Dea et al. 2008), was included because of its unusual morphology.

Disturbance events were simulated by placing 10 replicate colonies of each group on or in (depending on treatment) silty sand in an aquarium filled with sea water, and then moving a $15 \times 15 \mathrm{~cm}$ paddle back and forth through the water 10 times, approximately $5 \mathrm{~cm}$ above the sediment. The turbulence had the effect of throwing up the sediment, and turning over and bury- ing the colonies. This is considered to approximate the level of disturbance that benthic soft-bottom dwellers experience during feeding by a medium sized batoid, a process considered to be important in the lives of benthic animals. Care was taken to ensure that the force of each disturbance event was roughly equal among experimental runs; any differences should be equal across species, because all species were tested together.

Three treatments were prepared with the following initial orientations of the colonies: (1) Resting on top of the sediment upright, (2) on top of the sediment inverted and (3) buried under $1 \mathrm{~cm}$ of sediment upright (Fig. 6). The response to disturbance was measured by noting the final orientation in which the colonies were found after the water and sediment had settled, and classified into the same 3 categories (Fig. 6).

Each treatment comprised 10 replicate disturbance events. For each initial orientation, the mean proportion of the 3 possible final orientations of colonies following disturbance were calculated. From these proportions, 4 indexes were computed for each species (Fig. 6).

Before the experiment, morphometric data were gathered on each of the colonies used. Maximum and minimum diameter, height and shape (height/ median diameter) were measured, colonies were weighed and a calcification index was calculated following O'Dea et al. (2004). Mean colony diameter, height and shape of each group were correlated against the 4 indices of stability using Pearson moment product correlation.

Colony strength. To examine the relationship between colony morphology and colony strength, weights were placed on top of colonies until breakage occurred. The same 70 colonies were used as in the hydrodynamic experiment. Each colony was placed at

\begin{tabular}{|lll|}
\hline Index & Definition & $\begin{array}{l}\text { Mean proportion of colonies that maintain } \\
\text { an upright position above the sediment }\end{array}$ \\
$\begin{array}{l}\text { Resistance } \\
\text { to burial }\end{array}$ & $\begin{array}{l}\text { Mean proportion of colonies on the } \\
\text { surface that do not become buried }\end{array}$ \\
\hline Recovery & $\begin{array}{l}\text { Mean proportion of colonies that return } \\
\text { to an upright position above the sediment }\end{array}$ \\
Emergence & $\begin{array}{l}\text { Mean proportion of colonies that } \\
\text { emerge from burial }\end{array}$
\end{tabular}

Fig. 6. Experimental methodology used to measure the response of cupuladriid colonies to disturbance, and definition of indices 


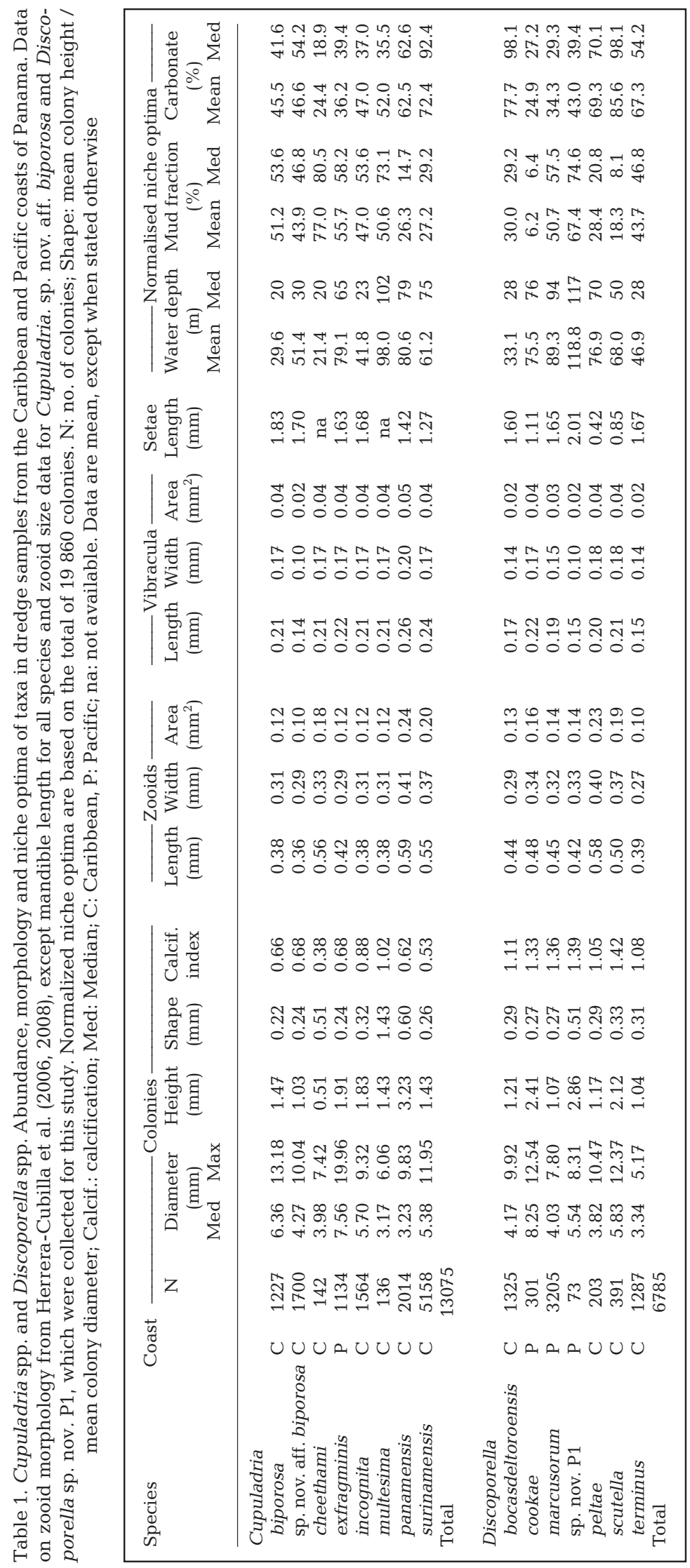

the base of a long, closed-bottom glass tube. Another, slightly narrower closed-bottom tube was placed within the former and lowered slowly until it rested on top of the colony. Weights were added to the internal tube until the colony fractured. The maximum sustainable load of the colony was the weight of the internal glass tube plus the weight of load prior to fracture. For the 2 very heavily calcified species (Discoporella sp. nov. 21 and sp. nov. 3) sufficient load could not be applied to cause breakage using the glass tube. In these cases, placing colonies on the floor and adding heavy weights was found to break them. When breakage occurred, the maximum sustainable load was calculated by replicating the weight on a bathroom scale to the nearest kilogram.

Mean maximum sustainable load was correlated against colony morphologies using Pearson moment product correlation (r). Additional morphometric data on zooid size was also included to observe if intra-colony morphologies played a significant role in colony strength. Zooid morphometrics were taken from Herrera-Cubilla et al. (2006 \& 2008), or measured from colonies in the case of undescribed species.

Locomotion over the sediment surface. The 'walking' speed of colonies was calculated from the distances traversed by undisturbed colonies. Aquaria were darkened, because cupuladriid colonies had previously shown an aversion to light. A total of 6 species were chosen, based upon the availability of healthy colonies, and 10 to 22 colonies of each were selected. Colonies were placed apex upwards upon silty sand in open seawater systems and their initial position recorded. After 4 to $7 \mathrm{~d}$, colony positions were redetermined and colony velocity (distance travelled per day) was calculated assuming that colonies had travelled in a straight line; colonies left faint trail marks in the sediment, and those that had meandered significantly were excluded.

For each species, mean velocity was calculated and the relationship between velocity and morphology was explored. Data considered important for locomotion included mandible length, colony diameter, height and shape. Morphometric data are presented in Table 1.

Locomotion and survival within the sediment. The ability of a colony to move through the sediment towards the surface after burial is likely to determine the types of habitat and intensity of bioturbation in which a species can survive. This ability was explored by measuring rates of emergence and of mortality following burial. The experiment was separated into 2 phases: 
Phase I was aimed to observe the abilities of different species to voluntarily emerge or survive when buried with sediment typical of in situ conditions. A layer of $2 \mathrm{~cm}$ of silty sand was placed on the bottom of 8 aquaria, upon which, in each aquarium, the colonies of a single species were placed apex upwards. Colonies were then buried by letting a further $2 \mathrm{~cm}$ of sediment slowly settle on top of the colonies, taking care not to disturb their positions (see Table 3 for species and number of colonies). Aquaria were maintained in an open seawater system for $31 \mathrm{~d}$ with water from the Gulf of Panama. Each day the colonies that emerged were counted and removed from the aquaria. After $31 \mathrm{~d}$, all colonies that had not emerged were sieved from the sediment and checked to determine if they were alive. For each species it was therefore possible to calculate the proportion of colonies emerged (number of emerged colonies / total number of col- onies) and the proportion of colony mortality among those buried (number of dead colonies / number of colonies that did not emerge). Cumulative emergence curves were also determined, based upon proportional data accounting for the total number of colonies used per species, and an index of emergence was calculated by summing the total area beneath each species' cumulative emergence curve.

Phase II tested how different sediment grain sizes affect the emergence and survival of a single species. The effect of different grain sizes on the ability of colonies to emerge and their survival during burial was assessed by repeating the burial experiment with colonies of Cupuladria exfragminis, but using coarse beach sand and sticky brown mud. A total of 30 separate colonies was used for each sediment type and the methods of burial of colonies; data collection and analysis were identical to those in Phase I.
A

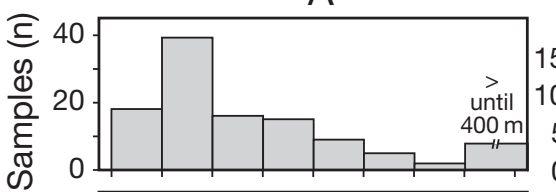

Caribbean C. biporosa

C. sp. nov. a. biporosa

C. cheethami

C. incognita

C. multesima

C. panamensis

C. surinamensis

D. bocasdeltoroensis

D. peltifera

D. scutella

D. terminata
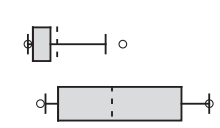

$\$$
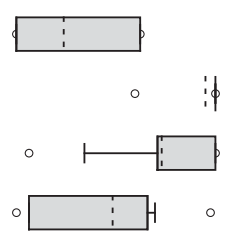

$+口 !$
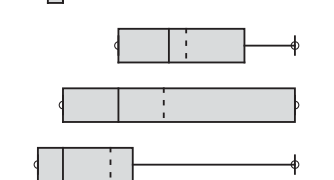

Pacific

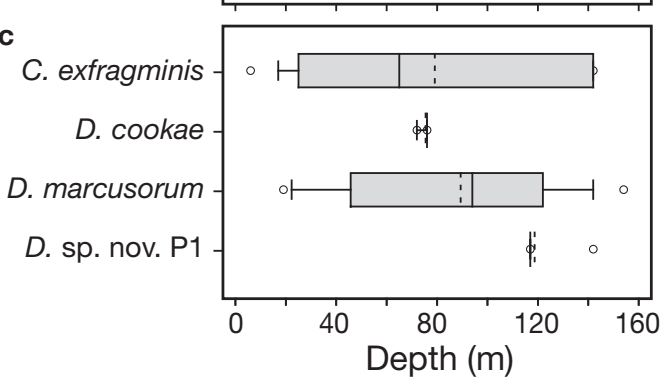

B
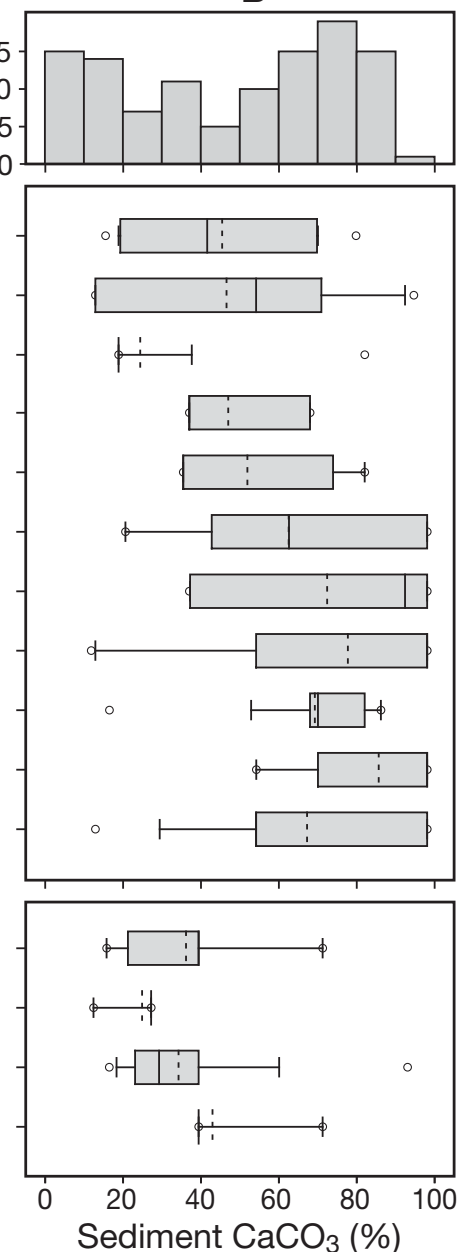

C

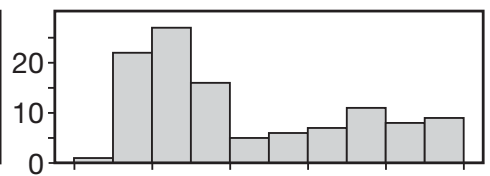

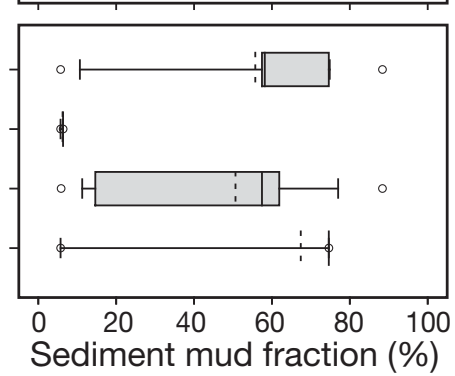

Fig. 7. Cupuladria spp. and Discoporella spp. Realised niches determined from abundances of colonies along gradients of (A) depth, (B) calcium carbonate content in sediments and (C) mud fraction in sediments. Plots show median (vertical line), mean (dashed vertical line) (where there is only 1 line the mean and median are identical), quartiles (box boundaries), 10th and 90th percentiles (whiskers) and 5th and 95th percentiles (dots). Abundance data were normalised by number of samples (shown in histogram at top) to account for uneven sampling intensities 


\section{RESULTS}

\section{Habitats}

A total of 19860 whole colonies were collected and 15 species identified from 193 dredge samples (Fig. 2; Table 1). The most abundant Caribbean species was Cupuladria surinamensis, and the most abundant Pacific species was Discoporella marcusorum. Abundance along water depth, \% mud fraction and $\%$ carbonate gradients shows high inter-specific variation (Table 1, Fig. 7). No evidence for multimodal distributions was observed in any in any of the environmental measures.

Species that are more abundant in deeper waters have significantly taller and more conical-shaped colonies (Fig. 8A,B), and are more heavily calcified than shallow water species (Table A1 in Appendix 1). No relationship was observed between calcification index and \% $\mathrm{CaCO}_{3}$.

Species that are more abundant in muddier regions have smaller zooids (Fig. 8C). Significant negative correlations were observed between \% mud fraction and zooid width and zooid area (Table A1). No clear relationships were recorded between any environmental gradient and vibraculum size in species (Table A1). Species most abundant in muddier environments have significantly longer mandibles (Fig. 8D); mandible length was not significantly correlated with any other environmental variable (Table A1).

\section{Orientation following disturbance}

The effect of disturbance on the orientation of colonies appears to be strongly determined by morphology (Tables 2 \& A2). Mean colony diameter and height were positively correlated with stability (Fig. 9A,B respectively) and diameter was correlated with recovery after burial (Fig. 9C). Wider and higher colonies are therefore more likely to maintain their upright position and wider colonies are more likely to return from an inverted to an upright position during a disturbance event. Conical colonies are more likely to passively emerge following burial (Fig. 9D), suggesting that colony shape has some functional significance in the ability of colonies to move vertically through sediment. Both colony diameter and height showed a positive, but non-signif-
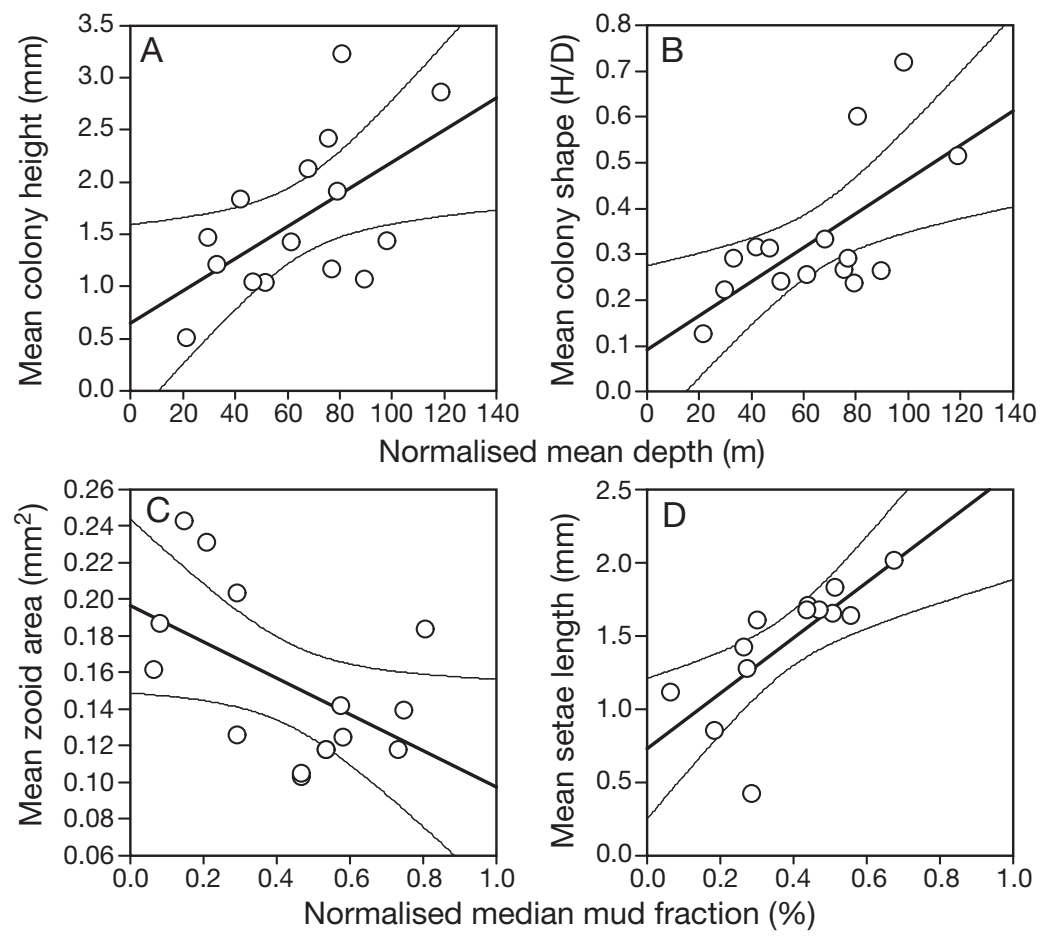

Fig. 8. Cupuladria spp. and Discoporella spp. Correlations between realised niche variables and morphology; thick line is Pearson product moment correlation, thin lines are 95\% confidence intervals. H/D: height/diameter. See Table A2 for coefficients and significance
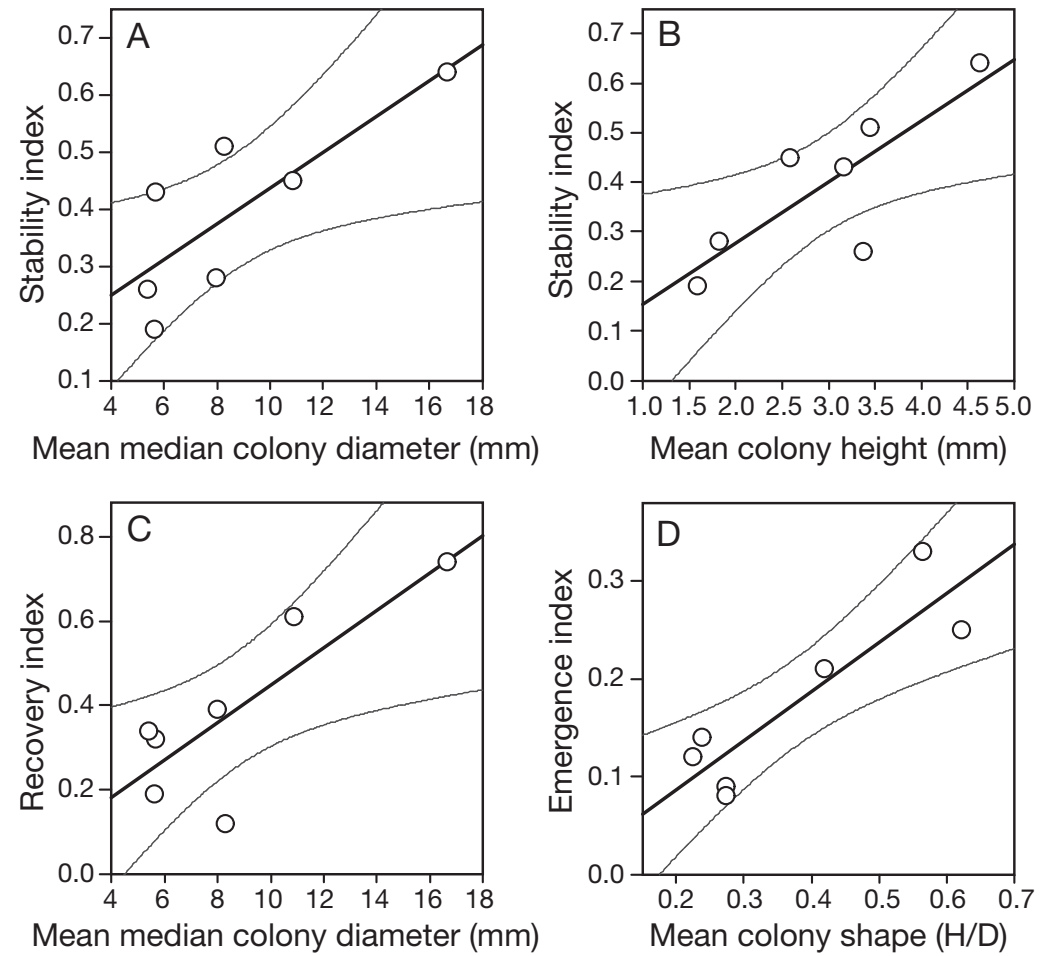

Mean median colony diameter $(\mathrm{mm})$

Fig. 9. Cupuladria spp. and Discoporella spp. Correlations between colony morphology and indices of response to disturbance; thick line is Pearson product moment correlation, thin lines are $95 \%$ confidence intervals. H/D: height/diameter. See Table A2 for coefficients and significance 


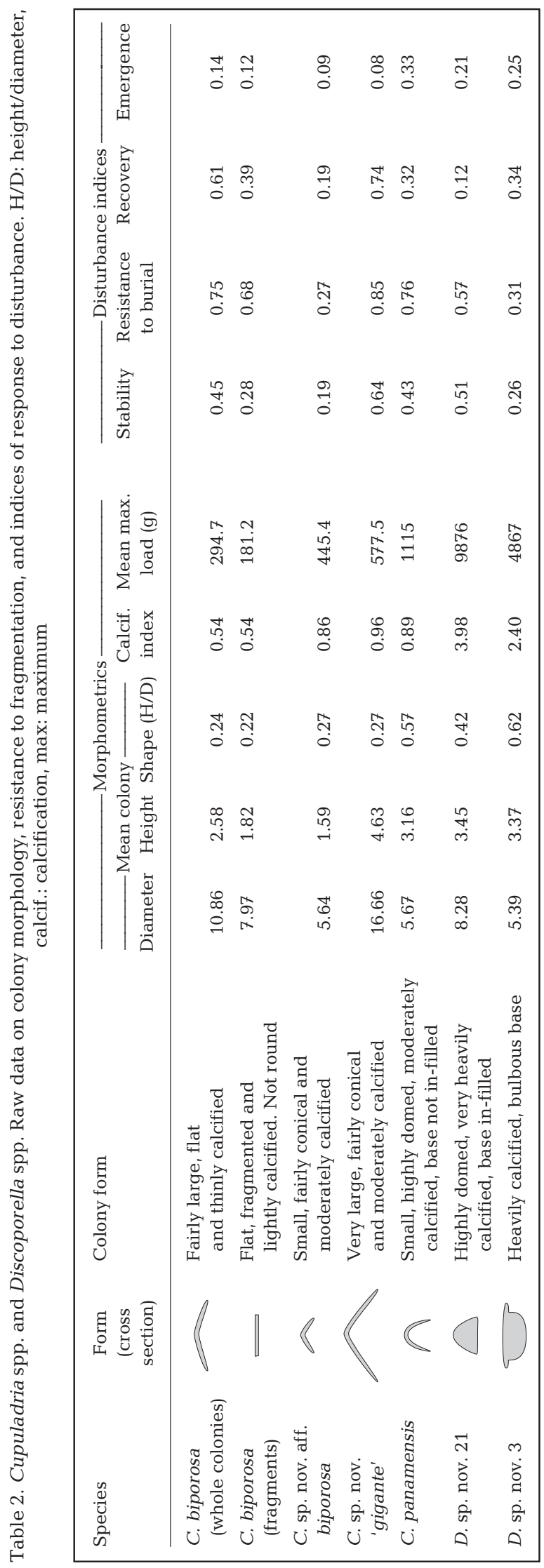

icant, correlation with resistance to burial (Table A2), suggesting that larger colonies either do not sink as easily as smaller colonies, or are more likely to passively emerge after burial. However, as colony diameter was negatively correlated with the emergence index (Table A2), the former appears more likely.

Calcification was not significantly correlated with any of the indices of response to disturbance (Table A2), although negative correlations with indices of resistance to burial as well as recovery suggest that denser colonies may have difficulty in returning to a 'normal' position during times of disturbance.

Fragments were considerably less stable, and less able to recover their position upon disturbance (Table 2). Since colony size is correlated with stability, the poor performance of fragments may in part be due to the fact that they were smaller than whole colonies.

\section{Colony strength}

The mean maximum sustainable load that colonies are able to support before breaking varied from $200 \mathrm{~g}$ to nearly $10 \mathrm{~kg}$ amongst species (Table 2 ). More heavily calcified colonies are more resistant to breakage, as are more conical colonies, (Table A2) although the latter relationship was not statistically significant and may be due to the fact that the most heavily calcified colonies tend to be dome-shaped (Tables $1 \& 2 ;$ O'Dea et al. 2004).

\section{Locomotion over the sediment surface}

The velocity of cupuladriid colonies over the sediment surface varied considerably both within and between species (Table A3; Fig. 10A). The fastest species, Discoporella sp. nov. P1, moves at speeds of around $5 \mathrm{~mm} \mathrm{~d}^{-1}$ and produces the smallest colonies; the slowest species, Cupuladria sp. nov. 'gigante', produces the largest colonies. However, no significant relationship was found between colony size and speed. A very highly significant positive correlation was observed between mean mandible length and speed (Fig. 10C). Inverted colonies of $C$. biporosa moved only slightly slower than colonies placed in a normal position (Fig. 10A,B). Fragments of $C$. biporosa placed in an inverted position showed the greatest velocity (Fig. 10B), while fragments placed in an upright position did not move at all.

\section{Locomotion and survival within the sediment}

Active emergence of cupuladriid colonies following burial under $2 \mathrm{~cm}$ of sediment was highly variable amongst species (Table 3), although in all species at 

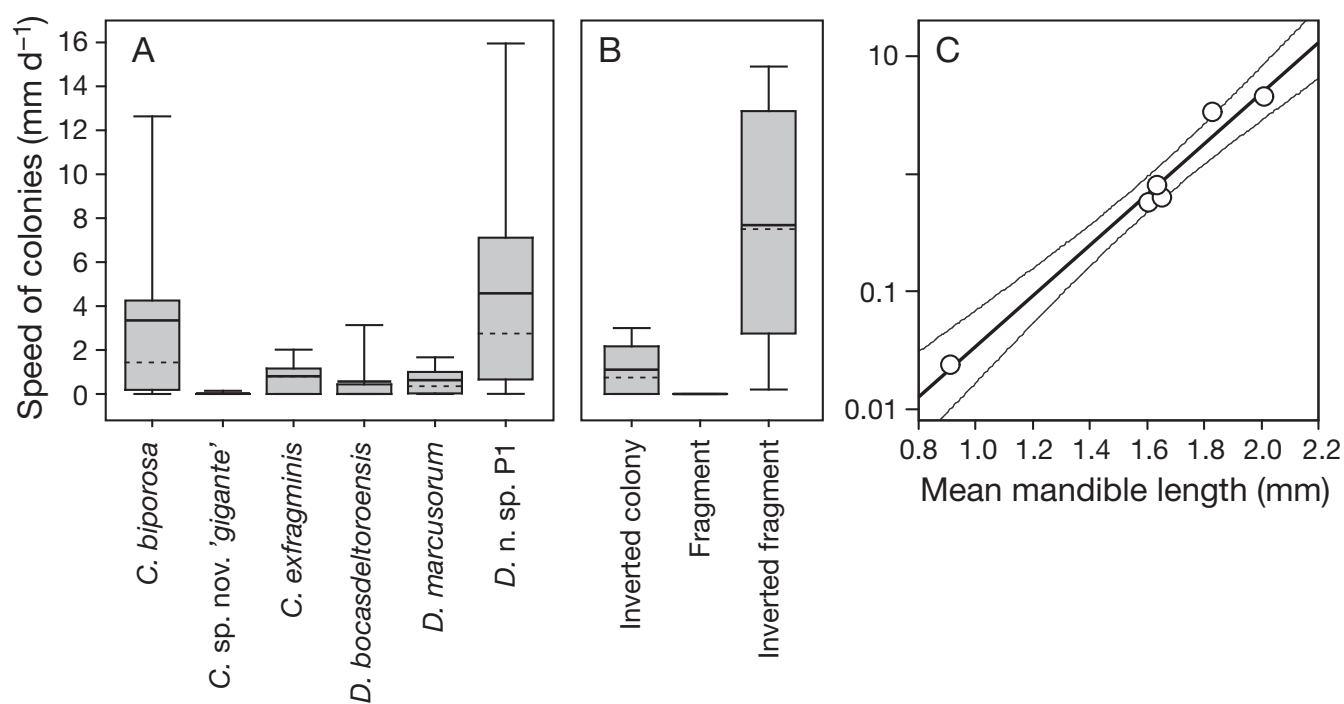

Fig. 10. Cupuladria spp. and Discoporella spp. Speed over sediment surfaces of (A) various colonies and (B) inverted colonies, fragments and inverted fragments of $C$. biporosa. Plots show median (horizontal line), mean (dashed horizontal line) (where there is only 1 line, the mean and median are identical), quartiles (box boundaries) and 5th and 95th percentiles (dots). (C) Correlation of mean mandible length and mean speed of movement between species; thick line is Pearson product moment correlation, thin lines are $95 \%$ confidence intervals. Note logarithmic scale for speed

least some colonies were able to emerge and most had an emergence of over $50 \%$ of the colonies after 30 to $31 \mathrm{~d}$ (Fig. 11). Could those species that emerge slowly better survive burial than those that emerge rapidly? A negative, but non-significant, relationship was found between the proportion of colonies that emerged and the proportion of mortality in the remaining colonies $(\mathrm{r}=-0.58 ; t=1.727 ; \mathrm{df}=6 ; \mathrm{p}=0.135)$. Species with longer mandibles survived burial for longer periods of time (Fig. 11C).

Sediment grain size influenced a colony's ability to emerge and survive burial (Fig. 11B). Emergence rates of Cupuladria exfragminis were highest in their native silty sand, where almost all the colonies emerged within $2 \mathrm{wk}$, intermediate in coarse sand, but very low in mud, where only 3 of the 30 colonies emerged (Fig. 11B, Table 3).

\section{Morphometrics}

Colony diameter varied 5-fold from the smallest species (Cupuladria multesima) to the largest (Cupuladria sp. nov. 'gigante'), colony shape ranged from almost flat (C. biporosa) to an isosceles profile (C. multesima), and the calcification of colonies varied from so thin that fragmentation occurs at the lightest touch (C. multesima), to so heavily calcified that it takes the weight of a
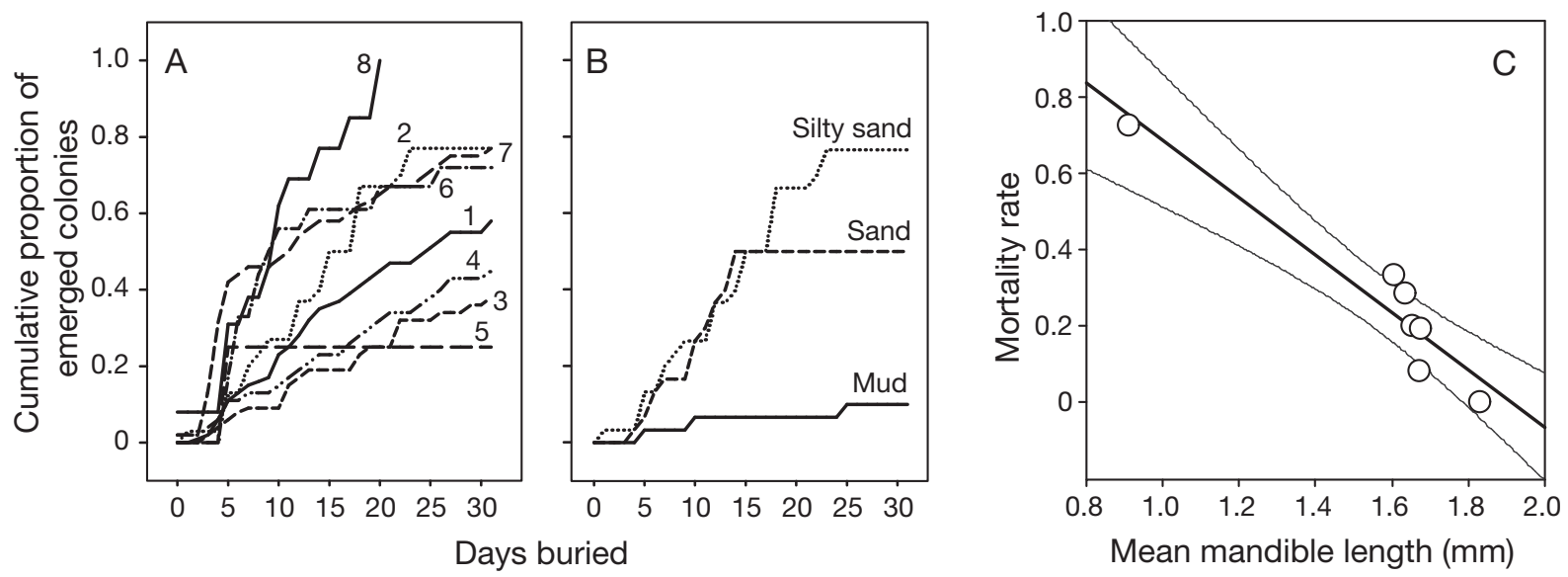

Fig. 11. Cupuladria spp. and Discoporella spp. Cumulative emergence curves for (A) various species buried in silty sand (numbers as in Table 3) and (B) C. biporosa buried in sediments of different grain sizes. (C) Correlation of mean mandible length and mortality rate following burial; thick line is Pearson product moment correlation, thin lines are $95 \%$ confidence intervals 
Table 3. Cupuladria spp. and Discoporella spp. Response to burial under $2 \mathrm{~cm}$ of sediment. Proportion of colonies emerged and emergence index demonstrate the ability of colonies to move through the sediment to the surface, while mortality (proportion) indicates the ability of colonies to live while buried for $31 \mathrm{~d}$. Numbers relate to cumulative curves presented in Fig. 11

\begin{tabular}{|c|c|c|c|c|c|c|}
\hline Expt & Species & $\mathrm{N}$ & $\begin{array}{c}\text { No. } \\
\text { emerged }\end{array}$ & $\begin{array}{c}\text { Proportion } \\
\text { emerged }\end{array}$ & $\begin{array}{c}\text { Emergence } \\
\text { index }\end{array}$ & Mortality \\
\hline \multicolumn{7}{|c|}{ Phase I (sandy silt) } \\
\hline \multicolumn{7}{|c|}{ Cupuladria } \\
\hline 1 & biporosa & 102 & 59 & 0.58 & 10.37 & 0.00 \\
\hline 2 & exfragminis & 30 & 23 & 0.77 & 14.53 & 0.29 \\
\hline 3 & sp. nov. 'gigante' & 53 & 20 & 0.38 & 6.17 & 0.73 \\
\hline 4 & incognita & 47 & 21 & 0.45 & 7.70 & 0.19 \\
\hline \multicolumn{7}{|c|}{ Discoporella } \\
\hline 5 & bocasdeltoroensis & 8 & 2 & 0.25 & 6.75 & 0.30 \\
\hline 6 & marcusorum & 18 & 13 & 0.72 & 16.06 & 0.20 \\
\hline 7 & terminus & 52 & 40 & 0.77 & 16.98 & 0.08 \\
\hline 8 & sp. nov. P1 & 13 & 13 & 1.00 & 21.77 & n.a. \\
\hline \multicolumn{7}{|c|}{ Phase II (C. biporosa) } \\
\hline 9 & Silty sand & 30 & 23 & 0.77 & 14.53 & 0.29 \\
\hline 10 & Sand & 30 & 15 & 0.50 & 11.07 & 0.13 \\
\hline 11 & Mud & 30 & 3 & 0.10 & 1.87 & 0.85 \\
\hline
\end{tabular}

separate cryptic species. Cupuladria biporosa, for example, is abundant in very shallow waters, while its morphologically similar cousin Cupuladria sp. nov. aff. biporosa has a distinctly deeper distribution (Fig. 7A). C. cheethami, Discoporella bocadeltoroensis and $D$. terminata parallel the very shallow depth distribution of C. biporosa, while the abundant $C$. surinamensis and the less common $C$. incognita occur in abundance at moderate water depths (Fig. 7A). In deeper Caribbean waters C. multesima, C. panamensis, D. peltifera and D. scutella are found in abundance (Fig. 7A). Cadée (1975) found $C$. biporosa in abundance on the Guyana Shelf in slightly deeper waters than found in this study, possibly because high terreginous inputs and fluctuations in salinity in the shallow waters shift species towards deeper water (Cadée 1975).

Species also separate along $\mathrm{CaCO}_{3}$ and mud gradients (Fig. 7B,C). The most striking pattern is that species tend to be abundant either in low carbonate and high mud environments, or high carbonate and low mud environments. This relationship is likely due to the negative relationship between mud and $\mathrm{CaCO}_{3}$, where high carbonate values normally originate from reefs, while reefs tend not be so structurally developed in areas of high silt input (D'Croz \& Robertson 1997, D'Croz et al. 2005). Low carbonate/high mud species include Cupuladria biporosa, Cupuladria sp. nov. aff. biporosa and $C$. cheethami, all of which are dominant in shallow waters. In Panama, these species tend to form large populations in coastal waters that are open to the ocean and influenced by terrestrial runoff, as they do in Guayana (Cadée 1975). Conversely, the other shallow water species, Discoporella terminus, is most abundant in high carbonate regions and associated with soft bottom habitats close to reefs. In addition to $D$. terminus the other high carbonate/low mud species are C. panamensis, C. surinamensis, D. bocasdeltoroensis, D. peltifera and D. scutella. Some occur in shallow and others in deeper waters, suggesting that a complex set of factors determine their realised niches.

Niche breadths are narrow and often exclusive in the Caribbean, but not in the Pacific. Interspecific competition should be lower in the Pacific because of reduced diversity (Dick et al. 2003, O'Dea et al. 2004, Herrera-Cubilla et al. 2006, 2008; Fig. 7) and the narrow niche breadths of the Caribbean may represent niche differentiation (Armstrong \& McGehee 1980) acting through spatial partitioning, which may not be as strong in the Pacific. 
Representative species of the genera, Cupuladria and Discoporella, have equally wide realised niches, demonstrating that no obvious niche separation exists between the 2 genera. Equally wide ranges in zooid and colony morphologies (Table 1) and rates of clonal propagation (O'Dea et al. 2008) signify overlapping habitats, modes of life, reproductive strategies and feeding ecologies, suggesting that both genera have undergone similar evolutionary processes.

\section{Hazards of sedimentation and epibiotics}

All bryozoans filter-feed with lophophores that need to extend away from the colony to create extraction and expellant currents (Okamura et al. 2001, Pratt 2004). Life on soft sediments therefore leads to 2 hazards that cupuladriids must overcome; smothering by sedimentation and epibiotic growth. The latter is particularly important, given that in soft sediment environments, cupuladriid colonies represent a scarce supply of hard substrate upon which epibiota may settle.

Storms on land greatly increase sedimentation rates to the benthos, often burying benthic organisms (Parsons-Hubbard et al. 1999), and even during times of clement weather, fine sediment and detritus will settle on the surface of epibenthic organisms. Encrusting bryozoans evade the problem by utilising protected habitats such as the under-surface of stones or corals, or surfaces where currents remove sediment, such as algal fronds (Jackson 1979, McKinney \& Jackson 1989), while erect growth is intrinsically better suited to the shedding of sediment with vertical rather than horizontally arranged frontal walls. Cupuladriids actively dislodge settling sediment with their mandibles (Busk 1859, Marcus \& Marcus 1962, Lagaaij 1963, Cook 1968, Cadée 1975, Winston 1988) and this may be why cupuladriids are able to thrive in low energy environments that are almost devoid of other epibenthic filter feeders. Sediments with high mud content typically reflect lower turbulence (Ferguson \& Church 2006) and cupuladriids with longer mandibles are more abundant in muddier sediments (Fig. 8D), strengthening the hypothesis that the active shedding of sediment is an important function of vibracula mandibles.

Colony shape may passively influence the amount of sediment that settles on the surface of a colony, because more highly domed colonies should find it easier to dislodge deposited sediment compared to flatter colonies. The inference therefore is that there is selection for domed colonies in areas of high sediment deposition, but this idea is weakened by the lack of any correlation between \% mud fraction and colony shape amongst species (Table A1). However, sedimentation rate is difficult to estimate from the environmental data collected, and
$\%$ mud is almost certainly not an accurate indicator of sedimentation. Highly domed species are more abundant in deeper waters (Fig. 8B), and although it is unlikely that sedimentation rates increase with water depth, sediments in deeper waters are generally finer.

Larvae and spores of epibiota are more problematic than sediment for free-living bryozoans. Colonies are often fouled by a variety of macroorganisms including hydroids, solitary corals, ascidians and other bryozoans, and microorganisms such as diatoms, algae and foraminifera (Winston 1988). Winston (1988) observed moulting of the cuticular frontal surface of zooids in Cupuladria doma, leading to the efficient sloughing off of fouling organisms. This presumably costly practice, apparently unique to the cupuladriids, demonstrates the importance of restricting epibiotic growth for survival. Areas of zooid mortality in a colony are often very heavily encrusted by larger fouling organisms, strongly suggesting that larvae of other encrusting species are deterred by mandibles or chemical methods in active regions of the colony (Dyrynda 1985). Mandibles may be stimulated to move when an animal larvae or algal spore attempts to settle, as mandibles flick violently if the colony surface is stimulated with a fine hair. If mandibles are unable to defend the entire colony from a settling organism, as can easily be imagined given their single plane of movement, the principle role of the mandible may be to disrupt the growth of already-settled organisms, preventing them from smothering the colony surface, which would impede the extension of lophophores (Winston 1988) and reduce oxygen diffusion to underlying zooids.

Cook (1963) thought that the principal function of vibracula mandibles in the Cupuladriidae was to clean the colony surface of sediment, and data presented here support this hypothesis (see above). However, allowing a larva or a spore to settle has the potential to be considerably more detrimental to the colony than allowing a similarly-sized grain of sand or detritus to fall on the colony surface. Therefore, the main role of the cupuladriid mandible is considered to be the prevention and/or removal of epibiotic growth. This conclusion is supported by the fact that mandibles in other bryozoans play defensive roles (Winston 1984, 1986, 1991), and maintaining an epibiont-free colony surface must be of considerable importance in bryozoans, given that lophophores are sometimes distracted from feeding to clean the colony surface (Shunatova \& Ostrovsky 2001, 2002).

\section{Disturbance and colony dynamics}

Free-living bryozoans may be disturbed by submarine currents (McCall 1978, Grant 1983) and the bio- 
turbation of sediments by larger benthic organisms such as polychaetes, molluscs, crustaceans and large demersal fish (Thayer 1983). The prevalence and strength of disturbance events is therefore related to myriad factors of the sedimentary and biological environment and difficult to measure. There is little evidence on which to construct hypotheses about the probable impact on cupuladriid communities or relative importance of bioturbation among habitats. For example, current-induced disturbance normally decreases with increasing water depth, while the abundance of demersal elasmobranchii, which are significant disturbers of the benthos, often increases with water depth on continental shelves (Navia et al. 2007). Despite these unknowns, this study suggests that cupuladriid species have several morphological adaptations that either prevent overturning, or assist colonies that have been overturned or buried to return to a normal position. These hypothesised adaptations can be categorised as either passive or active and shall be dealt with separately.

\section{Passive adaptations}

Large colonies are more stable than small colonies, which are easily flipped over because the basal area increases exponentially with diameter (following $\pi r^{2}$ ), while the area affected by leeward currents only increases linearly with diameter, following $\left(r^{2} \times h\right) / 2$ for a cone. Smaller colonies are therefore less stable during disturbance because the ratio of current-exposed colony surface to basal area is higher. Winston (1988) came to a similar conclusion after observing how flat and domed colonies behaved in flumes.

Mandible length is significantly longer in species with less wide colonies $(\mathrm{r}=-0.85 ; t=-3.227$; $\mathrm{df}=4$; $\mathrm{p}<0.05)$, suggesting that smaller species use long mandibles to increase their effective basal area and thus counteract the increased likelihood of being overturned. Mandibles of the small colonies of Discoporella sp. nov. P1 effectively triples the area of sediment the colony is in contact with from around 20 to $60 \mathrm{~mm}^{2}$ (see morphometric data in Table 1).

Another passive morphological adaptation is that more domed-shaped colonies are better able to move up through agitated sediment following burial, compared to flatter colonies (Fig. 9D), presumably because of decreased dynamic resistance. In active emergence experiments, conical colonies had significantly higher emergence indices than flatter colonies $(\mathrm{r}=0.682$; $t=2.798 ; \mathrm{df}=9 ; \mathrm{p}<0.05$ ) and wider colonies had significantly lower emergence indices than small colonies $(\mathrm{r}=-0.613 ; t=-2.328 ; \mathrm{df}=9 ; \mathrm{p}<0.05)$. Likewise, Ostrovsky et al. (2009) considered the ubiquitous trend from external to internal brooding observed in the evolutionary history of several unrelated free-living clades to represent an adaptation to decrease dynamic resistance caused by protruding ovicells. If colonies are frequently required to emerge from burial, reducing dynamic resistance is important in the evolution of motile free-living bryozoans.

\section{Active adaptations}

Burial experiments demonstrate that long mandibles are helpful for emergence. How lengthy mandibles improve a colony's ability to emerge is, however, not entirely clear. Longer mandibles appear to be more flexible, and species with long mandibles paradoxically have significantly smaller vibracula zooids (mean zooid area vs. mean mandible length; $\mathrm{r}=-0.53 ; t=2.16$; $\mathrm{df}=12 ; \mathrm{p}<0.05)$, suggesting that they also possess smaller adductor muscles powering the mandibles. Therefore, perhaps strength is not as important as the ability to create leverage, which longer mandibles should produce better, or alternatively more flexible mandibles may be easier to extrect if trapped by sediment.

It is more likely, however, that different mandible types have distinct functions. Long thin mandibles may be better suited to moving the colony through and over sediment, while short and thick mandibles may be built robustly to assist in the disruption of epibionts and may not be particularly functional for locomotion. Cupuladria sp. nov. 'gigante' has very large colonies yet very short mandibles; colonies are hardly able to move across the sediment surface (Table A3), they are inadequate at both active and passive emergence (Tables $2 \& 3$ ) and the species has the shortest, stiffest mandibles that do not curve downwards at the colony's margin, as is the case in many other species (Fig. 4). Cupuladria sp. nov. 'gigante' inhabits very shallow and clear waters where algal epibionts are likely to be much more of a problem than for species that inhabit deeper and muddier waters. Additionally, when deepwater species with long mandibles are kept in aquaria exposed to daylight, their mandibles quickly become encased in a mass of diatoms and other algae, something not observed in the shorter mandibles of shallowwater species.

\section{Surviving burial}

Mortality amongst buried colonies varied considerably amongst species. Only $27 \%$ of Cupuladria sp. nov. 'gigante' colonies survived burial, while all colonies of C. biporosa survived. Species with smaller zooids tend 
to survive longer than species with larger zooids (mean zooid area vs. proportion of mortality; $\mathrm{r}=0.91$; $t=4.91$; $\mathrm{df}=5 ; \mathrm{p}<0.01)$. Given the allometric scaling of metabolic rate with size (Hemmingsen 1960, SchmidtNielsen 1984), small body size is advantageous to benthic organisms completely buried by sediment, because of the increased advantage of a high surfacearea-to-volume ratio in a situation where oxygen is likely to be limited (Hinchey et al. 2006). How this process translates to colonial rather than solitary organisms, however, remains unexplored. Nonetheless, asphyxiation is the likely cause of cupuladriid mortality during burial. Survival was highest in increasingly porous sediments (fine black mud, silt, coarse sand), probably due to the lower levels of hypoxia. Lengthy mandibles may therefore help survive burial by increasing water agitation and thus reducing hypoxia.

\section{Adaptive controls on morphology}

Rate and type of clonal reproduction in cupuladriids is controlled by morphology (O'Dea et al. 2004, 2008), whilst the present study reveals how morphology correlates with life habit, behaviour and realised niche habitats. Which processes have been most important in driving morphological evolution of the free-living form?

Level of calcification of colonies was not correlated to any abiotic or biotic factor or mode of life feature measured in this study. Heavily calcified colonies are, however, much less susceptible to fragmentation (Table A2), and they clone less frequently (O'Dea et al. 2004). Consequently, differing levels of calcification most likely represent adaptations to different life history strategies, although the role of predation remains to be studied. Colony size greatly influences a colony's ability to effectively cope with disturbance, but colony size is also a function of life history, because regular cloning requires quasi-indeterminate growth, which should lead to the production of larger maximum colony sizes (as long as the process of fragmentation requires chance events). Colony shape shows a weak relationship with life history (O'Dea et al. 2004) whilst data presented here demonstrate that colony shape is particularly important in colony dynamics upon and within the sediment.

The development of vibracula mandibles was undoubtedly an important step in the evolutionary history of all mobile free-living bryozoa. Data presented here demonstrate that mandible morphology strongly influences a species' ability to inhabit different sea floor environments. All free-living bryozoans before the late Cretaceous were sessile (McKinney \& Jackson 1989) and their diversity on the whole was in decline through the Palaeozoic (Jackson \& McKinney 1990). Immobile free-living forms were still dominant at the end of the Cretaceous, but mobile forms soon replaced them (Jackson \& McKinney 1990), a process paralleled by similar evolutionary innovations in the free-living corals (Gill \& Coates 1977). The nearly synchronous appearance of mobility among unrelated cheilostome bryozoan groups and scleractinian corals suggests a common root cause. Jackson \& McKinney (1990) proposed that the driver was biotic, such as increased predation or bioturbation. There is no evidence that cupuladriids actively avoid predation. Colonies could feasibly tolerate semi-burial in order to escape predation and then emerge for feeding, but this is unlikely given that often feeding is restricted to zooids at the colony's margin, while central zooids frequently die; shallow submersion in sediment would bury marginal but not central zooids. Moreover, of the thousands of colonies observed in culture during this study, not one was seen to burrow.

Both infaunal life and the intensity of predation on other organisms has increased through both the Mesozoic and Cenozoic (Erwin 2008) and may well have been critical to the evolution of the free-living mode of life as sediments became more bioturbated through time. Indeed, there appears to be good temporal correlation between a hypothesised sharp increase in bioturbation at the end of the Mesozoic-as bottom waters became cooler and more oxygenated (MacLeod 1994)_and the evolution of the mobile free-living form, although this hypothesis requires further study.

\section{Locomotion}

Cupuladriids move slowly over the sediment surface (Marcus \& Marcus 1962, Cook 1963, Greeley 1967). None of the 'sophisticated' movements observed in the free-living Lunulitiids (Selenaria), whose colonies prop themselves high above the sediment surface, climb over objects, and right themselves if overturned (Cook \& Chimonides 1978, Chimonides \& Cook 1981) were noted in the present study. Perhaps, therefore, locomotion in cupuladriids is an unavoidable result of active mandibles performing other duties such as grooming.

Long mandibles do nonetheless increase colony speed, probably because of better leverage; mandibles also curve downwards towards the sediment suggesting deliberate mobility, although the need to rise above the surface to escape smothering may be a more obvious explanation. Colonies also show strong evidence of directional movement, as expected if movement is functional.

This leads to the conundrum of how buried colonies determine direction. They are clearly able to do so, 
because colonies buried upside down emerged right side up during this study (e.g. Fig. 1B) and no colonies were found at significantly deeper levels than those at which they were originally buried. Differential light levels might be used as cue, but cupuladriids, unlike the Selenaria, which move towards light (Cook \& Chimonides 1978), showed a strong aversion to light, moving away from both incandescent and solar light. No adult bryozoan is known to possess dedicated light sensitive organs, but sensitivity to light has been observed in free-living bryozoans (Berry \& Hayward 1984).

Speed of locomotion in cupuladriids is almost certainly too slow to be useful in escaping predation, and cupuladriids were not observed to burrow or hide in burrows, both common tactics to evade predation in motile epibenthic animals living on soft sediments (Thiel 1997).

\section{Colony mobility as an agent of dispersal}

Using the speeds measured in aquaria, and assuming an average colony age of 3 yr (O'Dea \& Jackson 2002), a colony could theoretically travel approximately $2 \mathrm{~m}$ in its lifetime (mean of all species) and a maximum of around $5 \mathrm{~m}$ (fastest species, Discoporella sp. nov. P1). Colony mobility is therefore not a realistic vector for dispersal. In contrast, Selenaria can progress at up to $1 \mathrm{~m} \mathrm{~h}^{-1}$ (Cook \& Chimonides 1978, Chimonides $\&$ Cook 1981) and hence $>25 \mathrm{~km}$ in 3 years.

All cupuladriid larvae are assumed to be lecithotrophic, larval life lasting 3 to $5 \mathrm{~d}$ (Cook \& Chimonides 1983) or less (Winston 1988), suggesting limited scope for larval dispersal (Cook \& Chimonides 1994). Disturbance or ingestion, transport and subsequent excretion (O'Dea et al. 2008) may be more important in dispersal. Palmer (1988) for example, found that the transport of meiofauna (e.g. benthic copepods, foraminiferans, nematodes) was doubled due to activities of fishes.

There is some evidence to suggest that species that propagate mostly sexually have more limited distributions than those that propagate clonally $\left(\mathrm{O}^{\prime}\right.$ Dea et al. 2004). Cupuladria exfragminis, for example, is a widely distributed species in the tropical eastern Pacific (O'Dea et al. 2004, Herrera-Cubilla et al. 2006) and propagates almost entirely asexually. If this species is very old, and individuals of populations have remained genetically homogenous for some time because of high rates of cloning, even slow and inefficient dispersal resulting from mobility and disturbance may be sufficient to explain its wide present-day distribution. Species that propagate mostly sexually should therefore be relatively limited in distribution because generation turnover is much faster and both phyletic evolution and speciation events should occur more frequently (Cheetham et al. 2001). The analysis of cupuladriid populations at the molecular level, combined with improved knowledge on distributions of fossil and modern day taxa, should make it possible to confirm this hypothesis.

\section{CONCLUSIONS}

Epibenthic life on soft-sediments is hazardous because of the high risks of smothering, disturbance and burial, and heavy pressure from fouling organisms and predators. The successful exploitation of this habitat by several bryozoan groups resulted from a variety of functional and behavioural traits that are unique to the free-living bryozoans.

Maintaining stability on the soft-sediment sea floor has been an important vector in the evolution of the free-living form. The most important adaptations include: (1) increasing colony stability, so that colonies are less likely to be overturned and buried, by increasing the ratio of basal area to colony height either with wider colonies or longer mandibles; (2) enhancing a colony's ability to emerge following burial, by increasing colony conicity and immersing protruding ovicells; (3) developing efficient methods of emergence following burial, with long mandibles used as digging apparatus. In all mobile free-living groups, vibracular mandibles were present in colonies of their erect or encrusting ancestors, in which their function was probably defensive. Defence from settling epibionts remains important in shallow water species, whilst the digging role of mandibles has been critical to the survival of epibenthic filter feeders that have evolved in increasingly bioturbated environments.

Therefore, both the form and habit of mobile freeliving bryozoans have been likely shaped by life on unstable sediments, where disturbance and burial are considerable threats. The shift from sessile free-living to mobile free-living bryozoans from the Mesozoic to the Cenozoic is likely to have been driven by a shift in the intensity or type of disturbance, probably by increasing intensity and/or changes in the nature of bioturbation.

Acknowledgements. J. B. C. Jackson was instrumental in the conception of this study and F. Rodríguez helped in myriad ways with its implementation. B. DeGracia and Y. DelValle sorted thousands of bryozoan colonies. Collections were made by many, including M. Dick, H. Fortunato, A. Herrera, J. Jara, M. Pacheco, L. Ramalho, T. Smith and the crew of RV 'Urraca'. W. Green and S. Punyasena helped with statistical analyses. J. Ceballos helped produce the scanning electron micrographs. The manuscript benefited greatly from discussion and comments from A. N. Ostrovsky, S. Jagadeeshan, B. 
Okamura, P. D. Taylor and 3 anonymous reviewers. I would like to thank the Republic of Panama and the Kuna Nation for permission to collect. Financial support was provided by the Tupper fellowship program at the Smithsonian Tropical Research Institute, National Science Foundation grant (EAR03-45471), SENACYT and a National Geographic Exploration Grant.

\section{LITERATURE CITED}

Armstrong RA, McGehee R (1980) Competitive exclusion. Am Nat 115:151-170

Baluk W, Radwanski A (1977) The colony regeneration and life habitat of free-living bryozoans, Cupuladria canariensis (Busk) and C. haidingeri (Reuss) from the Korytnica Clays (Middle Miocene): Holy Cross Mountains, Poland. Acta Geol Pol 27:143-156

Berry MS, Hayward PJ (1984) Nervous and behavioural responses to light in colonies of the free-living bryozoan, Selenaria maculata (Busk). Cell Mol Life Sci 40:108-110

Busk G (1859) A monograph of the fossil Polyzoa of the Crag. Palaeontograph Soc Monogr Lond

Cadée GC (1975) Lunulitiform bryozoa from the Guyana shelf. Neth J Sea Res 9:320-343

Cheetham AH, Jackson JBC, Sanner J (2001) Evolutionary significance of sexual and asexual modes of propagation in Neogene species of the bryozoan Metrarabdotos in tropical America. J Paleontol 75:564-577

Chimonides PJ, Cook PL (1981) Observations on living colonies of Selenaria (Bryozoa, Cheilostomata). II. Cah Biol Mar 22:207-219

Cook PL (1963) Observations on live lunulitiform zoaria of Polyzoa. Cah Biol Mar 4:407-413

Cook PL (1965) Notes on the Cupuladriidae (Polyzoa, Anasca). Bull Br Mus (Nat Hist) Zool 13:151-187

Cook PL (1968) Bryozoa (Polyzoa) from the coasts of tropical west Africa. Atl Rep 10:115-262

Cook PL, Chimonides PJ (1978) Observations on living colonies of Selenaria (Bryozoa, Cheilostomata) I. Cah Biol Mar 19:147-158

Cook PL, Chimonides PJ (1983) A short history of the lunulite Bryozoa. Bull Mar Sci 33:566-581

Cook PL, Chimonides PJ (1994) Notes on the family Cupuladriidae (Bryozoa), and on Cupuladria remota sp. n. from the Marquesas Islands. Zool Scr 23:251-268

D'Croz L, Del Rosario JB, Góndola P (2005) The effect of fresh water runoff on the distribution of dissolved inorganic nutrients and plankton in the Bocas del Toro Archipelago, Caribbean Panama. Caribb J Sci 41:414-429

Dartevelle E (1932) Contribution a l'etude des Bryozoaires fossiles de l'Eocene de la Belgique. Ann Soc R Zool Belg LXIII: 70-72

D'Croz L, Robertson DR (1997) Coastal oceanographic conditions affecting coral reefs on both sides of the Isthmus of Panama. Proc 8th Int Coral Reef Symp 2:2053-2058

Dick MH, Herrera Cubilla A, Jackson JBC (2003) Molecular phylogeny and phylogeography of free-living Bryozoa (Cupuladriidae) from both sides of the Isthmus of Panama. Mol Phylogenet Evol 27:355-371

Driscoll EG, Gibson JW, Mitchell SW (1971) Larval selection of substrate by the Bryozoa Discoporella and Cupuladria. Hydrobiologia 37:347-359

Dyrynda PEJ (1985) Functional allelochemistry in temperate waters: chemical defences of bryozoans. In: Nielsen $C_{\text {, }}$ Larwood GP (eds) Bryozoa: Ordovician to Recent. Olsen \& Olsen, Fredensborg, p 95-100
Erwin DH (2008) Macroevolution of ecosystem engineering, niche construction and diversity. Trends Ecol Evol 23: 304-310

Ferguson RI, Church M (2004) A simple universal equation for grain settling velocity. J Sediment Res 74:933-937

Gill GA, Coates AG (1977) Mobility, growth patterns and substrate in some fossil and recent corals. Lethaia 10:119-134

- Grant J (1983) The relative magnitude of biological and physical sediment reworking in an intertidal community. J Mar Res 41:673-689

- Greeley R (1967) Natural orientation of lunulitiform bryozoans. Geol Soc Am Bull 78:1179-1182

Hageman SJ, Bock PE, Bone Y, McGowran B (1998) Bryozoan growth habits: classification and analysis. J Paleontol 72:418-436

Håkansson E, Thomsen E (2001). Asexual propagation in cheilostome Bryozoa: evolutionary trends in a major group of colonial animals. In: Jackson JBC, Lidgard S, McKinney FK (eds) Evolutionary patterns: growth, form and tempo in the fossil record. University of Chicago Press, Chicago, IL, p 326-347

Håkansson E, Voigt E (1996) New free-living bryozoans from the northwest European Chalk. Bull Geol Soc Den 42: $187-207$

Hemmingsen AM (1960) Energy metabolism as related to body size and respiratory surfaces and its evolution. Rep Steno Memorial Hosp Nord Insulin Lab 4:1-110

Herrera-Cubilla A, Dick MH, Sanner J, Jackson JBC (2006) Neogene Cupuladriidae of tropical America. I. Taxonomy of recent Cupuladria from opposite sides of the Isthmus of Panama. J Paleontol 80:245-263

$>$ Herrera-Cubilla A, Dick MH, Sanner J, Jackson JBC (2008) Neogene Cupuladriidae of tropical America. II. Taxonomy of recent Discoporella from opposite sides of the Isthmus of Panama. J Paleontol 82:279-298

$>$ Hinchey EK, Schaffner SC, Hoar CC, Vogt BW, Batte LP (2006) Responses of estuarine benthic invertebrates to sediment burial: the importance of mobility and adaptation. Hydrobiologia 556:85-98

Hoare K, Hughes RN, Goldson AJ (1999) Molecular genetic evidence for the prevalence of outcrossing in the hermaphroditic brooding bryozoan Celleporella hyalina. Mar Ecol Prog Ser 188:73-79

Huey RB, Carlson M, Crozier L, Frazier M and others (2002) Plants versus animals: Do they deal with stress in different ways? Integr Comp Biol 42:415-423

Hutchinson GE (1965) The niche: an abstractly inhabited hypervolume. In: Hutchinson GE (ed) The ecological theatre and the evolutionary play. Yale University Press, New Haven, CT, p 26-78

Hutchinson GE (1957) Concluding remarks. Cold Spring Harb Symp Quant Biol 22:415-427

Jackson JBC (1979) Morphological strategies of sessile animals. In: Larwood G, Rosen BR (eds) Biology and systematics of colonial organisms. Academic Press, London, p 499-555

Jackson JBC, McKinney FK (1990) Ecological processes and progressive macroevolution of marine clonal benthos. In: Ross RM, Allman WD (eds) Causes of evolution, a paleontological perspective. University of Chicago Press, Chicago, IL, p 173-209

Keough MJ, Chernoff H (1987) Dispersal and population variation in the bryozoan Bugula neritina. Ecology 68:199-210

Lagaaij R (1963) Cupuladria canariensis (Busk) - portrait of a bryozoan. Palaeontology 6:172-217

MacLeod KG (1994) Bioturbation, inoceramid extinction, and mid-Maastrichtian ecological change. Geology 22:139-142 
Marcus E, Marcus E (1962) On some lunulitiform Bryozoa. Univ São Paulo Bol Fac Philos Sci Letr Zool 3:111-353

McCall PL (1978) Spatial-temporal distributions of Long Island Sound inferno: the role of bottom disturbance in a near shore marine habitat. In: Wiley ML (ed) Estuarine interactions. Academic Press, New York

McKinney FK, Jackson JBC (1989) Bryozoan evolution. Unwin Hyman, Boston

Navia AF, Mejia-Falla PA, Giraldo A (2007) Feeding ecology of elasmobranch fishes in coastal waters of the Colombian Eastern Tropical Pacific. BMC Ecol 7:1-10

O'Connor RJ, Boaden PJS, Seed R (1975) Niche breadth in Bryozoa as a test of competition theory. Nature 256:307-309

O'Dea A, Jackson JBC (2002) Bryozoan growth mirrors contrasting seasonal regimes across the Isthmus of Panama. Palaeogeogr Palaeoclimatol Palaeoecol 185:77-94

O'Dea A, Herrera-Cubilla A, Fortunato H, Jackson JBC (2004) Life history variation in cupuladriid bryozoans from either side of the Isthmus of Panama. Mar Ecol Prog Ser 280: 145-161

O'Dea A, Jackson JBC, Fortunato H, Smith T, D'Croz L, Johnson KG, Todd J (2007) Environmental change preceded Caribbean mass extinction by 2 million years. Proc Natl Acad Sci USA 104:5501-5506

O'Dea A, Jackson JBC, Taylor PD, Rodríguez F (2008) Modes of reproduction in recent and fossil cupuladriid bryozoans. Palaeontology 51:847-864

Okamura B, Harmelin JG, Jackson JBC (2001) Refuges revisited: enemies versus flow and feeding as determinants of sessile animal distribution and form. In: Jackson JBC, Lidgard S, McKinney FK (eds) Evolutionary patterns: growth, form and tempo in the fossil record. University of Chicago Press, Chicago, IL, p 61-93

Ostrovsky AN, O'Dea A, Rodriguez F (2009) Comparative anatomy of internal incubational sacs in cupuladriid byrozoans and the evolution of brooding in free-living cheilostomes. J Morphol doi: 10.1002/jmor.10767

Palmer MA (1988) Dispersal of marine meiofauna: a review and conceptual model explaining passive transport and active emergence with implications for recruitment. Mar Ecol Prog Ser 48:81-91
Parsons-Hubbard KM, Callender WR, Powell EN, Brett CE, Walker SE, Raymond AL, Staff GM (1999) Rates of burial and disturbance of experimentally-deployed molluscs: implications for preservation potential. Palaios 14:337-351

Porter JS, Ryland JS, Carvalho GR (2002) Micro- and macrogeographic genetic structure in bryozoans with different larval strategies. J Exp Mar Biol Ecol 272:119-130

Pratt MC (2004) Effect of zooid spacing on bryozoan feeding success: is competition or facilitation more important? Biol Bull Woods Hole 207:17-27

Ryland JS (1970) Bryozoans. Hutchinson University Library, London

Schmidt-Nielsen K (1984) Scaling: Why is animal size so important? Cambridge University Press, Cambridge

Shunatova NN, Ostrovsky AN (2001) Individual autozooidal behaviour and feeding in marine bryozoans. Sarsia 86: 112-142

Shunatova NN, Ostrovsky AN (2002) Group autozooidal behaviour and chimneys in marine bryozoans. Mar Biol 140:503-518

Thayer CW (1983) Sediment mediated biological disturbance and the evolution of marine benthos. In: Tevesz MJS, McCall PL (eds) Biotic interactions in recent and fossil benthic communities. Plenum Press, New York, p 479-625

Thiel M (1997) Epibenthic predation in marine soft-bottoms: being small and how to get away with it. Hydrobiologia 355:11-19

Thomsen E, Håkansson E (1995) Sexual versus asexual dispersal in clonal animals-examples from cheilostome bryozoans. Paleobiology 21:496-508

Winston JE (1984) Why bryozoans have avicularia - a review of the evidence. Am Mus Novit 2789:1-26

Winston JE (1986) Victims of avicularia. PSZN I: Mar Ecol $7: 193-199$

Winston JE (1988) Life histories of free-living bryozoans. Natl Geogr Res 4:528-539

Winston JE (1991) Avicularian behaviour-a progress report. In: Bigey FP, d'Hondt JL (eds) Bryozoaires actuels et fossiles: Bryozoa living and fossil. Bull Soc Sci Nat Ouest Fr Mém HS 1:531-540

Appendix 1. Variations in colony morphologies, realised niches and colony behaviour in tropical American cupuladriid bryozoans

Table A1. Pearson product moment correlation coefficients (r) of environmental optima against cupuladriid morphology; $t$-test $(\mathrm{n}=15$, except for setae length $\mathrm{n}=13)$; $\mathrm{ns}=$ not significant, ${ }^{*} \mathrm{p}<0.05,{ }^{* *} \mathrm{p}<0.01$. Calcif.: calcification, Max.: maximum

\begin{tabular}{|c|c|c|c|c|c|c|c|c|c|c|c|c|c|}
\hline \multirow{2}{*}{ Variable } & & \multicolumn{5}{|c|}{ Colonies } & \multicolumn{3}{|c|}{ _ Zooids } & \multicolumn{3}{|c|}{ _ Vibracula $ـ$} & \multirow{2}{*}{$\begin{array}{c}\text { Setae } \\
\text { length } \\
(\mathrm{mm})\end{array}$} \\
\hline & & $\begin{array}{c}\text { Diam } \\
\text { Median }\end{array}$ & $\begin{array}{l}\text { leter } \\
\text { Max. }\end{array}$ & Height & Shape & $\begin{array}{l}\text { Calcif. } \\
\text { index }\end{array}$ & Length & Width & Area & Length & Width & Area & \\
\hline \multirow{2}{*}{$\begin{array}{l}\text { Water } \\
\text { depth }\end{array}$} & Mean & $0.03^{\mathrm{ns}}$ & $0.57^{*}$ & $0.65^{*}$ & $0.00^{\mathrm{ns}}$ & $0.52^{*}$ & $0.05^{\mathrm{ns}}$ & $0.31^{\mathrm{ns}}$ & $0.16^{\mathrm{ns}}$ & $0.05^{\mathrm{ns}}$ & $-0.07^{\mathrm{ns}}$ & $0.01^{\mathrm{ns}}$ & $-0.08^{\text {ns }}$ \\
\hline & Median & $0.00^{\mathrm{ns}}$ & $0.50^{\mathrm{ns}}$ & $0.62^{*}$ & $-0.05^{\mathrm{ns}}$ & $0.43^{\mathrm{ns}}$ & $0.19^{\mathrm{ns}}$ & $0.38^{\mathrm{ns}}$ & $0.27^{\mathrm{ns}}$ & $0.19^{\mathrm{ns}}$ & $0.01^{\mathrm{ns}}$ & $0.11^{\mathrm{ns}}$ & $-0.10^{\mathrm{ns}}$ \\
\hline \multirow{2}{*}{$\begin{array}{l}\text { Mud } \\
\text { fraction }\end{array}$} & Mean & $-0.21^{\mathrm{ns}}$ & $-0.32^{\mathrm{ns}}$ & $-0.05^{\mathrm{ns}}$ & $-0.22^{\mathrm{ns}}$ & $-0.31^{\mathrm{ns}}$ & $-0.32^{\mathrm{ns}}$ & $-0.43^{\mathrm{ns}}$ & $-0.39^{\mathrm{ns}}$ & $-0.30^{\mathrm{ns}}$ & $-0.33^{\mathrm{ns}}$ & $-0.34^{\mathrm{ns}}$ & $0.74^{* *}$ \\
\hline & Median & $-0.20^{\mathrm{ns}}$ & $-0.35^{\mathrm{ns}}$ & $0.05^{\mathrm{ns}}$ & $-0.29^{\text {ns }}$ & $-0.23^{\mathrm{ns}}$ & $-0.46^{\mathrm{ns}}$ & $-0.53^{*}$ & $-0.52^{*}$ & $-0.33^{\mathrm{ns}}$ & $-0.35^{\mathrm{ns}}$ & $-0.37^{\mathrm{ns}}$ & $0.78^{* *}$ \\
\hline \multirow[t]{2}{*}{ Carbonate } & Mean & $-0.35^{\mathrm{ns}}$ & $0.04^{\mathrm{ns}}$ & $0.21^{\mathrm{ns}}$ & $-0.07^{\mathrm{ns}}$ & $0.15^{\mathrm{ns}}$ & $0.22^{\mathrm{ns}}$ & $0.29^{\text {ns }}$ & $0.28^{\mathrm{ns}}$ & $0.02^{\mathrm{ns}}$ & $0.06^{\mathrm{ns}}$ & $0.04^{\mathrm{ns}}$ & $-0.42^{\mathrm{ns}}$ \\
\hline & Median & $-0.15^{\mathrm{ns}}$ & $0.05^{\mathrm{ns}}$ & $0.01^{\mathrm{ns}}$ & $0.14^{\mathrm{ns}}$ & $0.09^{\mathrm{ns}}$ & $0.30^{\mathrm{ns}}$ & $0.32^{\text {ns }}$ & $0.33^{\mathrm{ns}}$ & $0.04^{\mathrm{ns}}$ & $0.00^{\mathrm{ns}}$ & $0.03^{\mathrm{ns}}$ & $-0.44^{\mathrm{ns}}$ \\
\hline
\end{tabular}


Table A2. Pearson product moment correlation coefficients (r) of colony morphology against indices of passive response to disturbance and maximum sustainable load before breakage ( $t$-test). Calcif.: calcification. Data are mean; ns: not significant, ${ }^{*} \mathrm{p}<0.05,{ }^{* * *} \mathrm{p}<0.001$

\begin{tabular}{|lcccc|}
\hline Index & $\begin{array}{c}\text { Median } \\
\text { diameter }\end{array}$ & Height & Shape & $\begin{array}{c}\text { Calcif. } \\
\text { index }\end{array}$ \\
\hline Stability & $0.80^{*}$ & $0.81^{*}$ & $-0.10^{\mathrm{ns}}$ & $0.16^{\mathrm{ns}}$ \\
Resistance to burial & $0.68^{\mathrm{ns}}$ & $0.44^{\mathrm{ns}}$ & $-0.29^{\mathrm{ns}}$ & $-0.33^{\mathrm{ns}}$ \\
Recovery & $0.82^{*}$ & $0.44^{\mathrm{ns}}$ & $-0.38^{\mathrm{ns}}$ & $-0.56^{\mathrm{ns}}$ \\
Emergence & $-0.56^{\mathrm{ns}}$ & $0.19^{\mathrm{ns}}$ & $0.89^{*}$ & $0.35^{\mathrm{ns}}$ \\
Maximum load & $-0.21^{\mathrm{ns}}$ & $0.32^{\mathrm{ns}}$ & $0.47^{\mathrm{ns}}$ & $0.99^{* * *}$ \\
\hline
\end{tabular}

Editorial responsibility: Otto Kinne, Oldendorf/Luhe, Germany
Table A3. Cupuladria spp. and Discoporella spp. Speed of movement on the sediment (mean $\pm \mathrm{SD}$ ); whole colonies placed upright upon sediment, unless otherwise stated

\begin{tabular}{|lccl|}
\hline Species & $\mathrm{N}$ & $\begin{array}{c}\text { Speed } \\
\left(\mathrm{mm} \mathrm{d}^{-1}\right)\end{array}$ & \\
\hline C. biporosa & 22 & $3.35 \pm 4.70$ & \\
& 20 & $1.11 \pm 1.17$ & Colony inverted \\
& 10 & 0 & Fragment \\
C. exfragminis & 10 & $7.68 \pm 5.35$ & Fragment inverted \\
C. sp. nov. 'gigante' & 10 & $0.81 \pm 0.72$ & \\
D. bocasdeltoroensis & 20 & $0.02 \pm 0.09$ & \\
D. marcusorum & 22 & $0.63 \pm 0.75$ & \\
D. sp. nov. P1 & 10 & $4.58 \pm 5.53$ & \\
\hline
\end{tabular}

Submitted: February 13, 2009; Accepted: July 1, 2009 Proofs received from author(s): August 13, 2009 